\title{
The Effect of Mechanical Activation on the Stabilization of Ash Properties of Krasnoyarsk CHP
}

\author{
Irina G. Endzhievskaya, \\ Nina G. Vasilovskaya, Olga G. Dubrovskaya, \\ Galina P. Baranova and Alena A. Chudaeva* \\ Siberian Federal University \\ 79 Svobodny, Krasnoyarsk, 660041, Russia
}

Received 15.06.2018, received in revised form 18.06.2018, accepted 12.10.2018

In this article the genesis of the technogenic product that determines its composition, structure, state, and properties is analyzed. The possibility of using technogenic waste from Krasnoyarsk HPS in the production of building materials was considered. It is shown that considerable fluctuations in the chemical composition and structure of the ash of CHP-2 necessitate additional influence on it in order to stabilize the composition and properties, and also to prevent the negative effect of $\mathrm{CaO}$, caused by late hydration due to the vitreous surface shell. To remove the danger of destructive processes in hardening products of ash-based building materials by neutralizing free calcium oxide, as the primary causes of stone structure defects, stabilization of ash composition and the possibility of using it as a filler in cement compositions (concretes, solutions), it is advisable to activate it in a hydrodynamic disperser. A study of the phase composition of hardening products of cement-free ash-free formulations showed that after activation it is more homogeneous, with a small number of reflections, which indicates greater homogeneity and stability of the structure. The increase in strength characteristics is also related to the uniformity of the change in the volume of activated ash.

Keywords: ashes of Krasnoyarsk CHP, chemical composition, mineralogical composition, phase composition, physical and mechanical properties, cavitation, hydrodynamic dispersant, bending strength, compressive strength.

Citation: Endzhievskaya I.G., Vasilovskaya N.G., Dubrovskaya O.G., Baranova G.P., Chudaeva A.A. The effect of mechanical activation on the stabilization of ash properties of Krasnoyarsk CHP, J. Sib. Fed. Univ. Eng. technol., 2018, 11(7), $842-855$. DOI: $10.17516 / 1999-494 X-0099$.

(C) Siberian Federal University. All rights reserved

This work is licensed under a Creative Commons Attribution-NonCommercial 4.0 International License (CC BY-NC 4.0).

* Corresponding author E-mail address: putinap@mail.ru, icaend@mail.ru 


\title{
Влияние механоактивации на стабилизацию свойств золы уноса Красноярских ТЭЦ
}

\author{
И.Г. Енджиевская*, Н.Г. Василовская, \\ О.Г. Дубровская, Г.П. Баранова, А.А. Чудаева \\ Сибирский федеральный университет \\ Россия, 660041, Красноярск, пр. Свободный, 79
}

В данной статье анализировался генезис техногенного продукта, определяющий его состав, структуру, состояние, свойства. Рассматривалась возможность использования техногенных отходов Красноярских ТЭЦ в производстве строительных материалов. Показано, что значительные колебания в химическом составе и строении золь ТЭЦ-2 обусловливают необходимость дополнительного воздействия на нее в целях стабилизации состава и свойств, а также для предотвращения негативного влияния СаО овоб, вызванного поздними сроками гидратирования из-за стекловидной поверхностной оболочки. Для снятия опасности деструктивных процессов в продуктах твердения строительных материалов на основе золы путем нейтрализации свободного оксида кальиия, как первопричины дефектов структуры камня, стабилизации состава золы и возможности использования ее в качестве наполнителя в цементных композициях (бетонах, растворах) целесообразно активировать ее в гидродинамическом диспергаторе. Изучение фазового состава продуктов твердения бесиементных составов на основе золь показало, что после активачии он более однородный, с мальм количеством отражений, что свидетельствует о большей гомогенности и стабильности структуры. Повышение прочностных характеристик связано в том числе с равномерностью изменения объема активированной золь.

Ключевые слова: золь Красноярских ТЭЦ, химический состав, минералогический состав, фазовый состав, физико-механические свойства, кавитаиия, гидродинамический диспергатор, прочность при изгибе, прочность при сжатии.

\section{Введение}

В последние годы экологические проблемы приобретают все большую актуальность и являются предметом многих современных научных исследований. К ним относятся: изменение климата под воздействием выбросов парниковых газов в результате сжигания органического топлива, истощение озонового слоя, кислотные дожди, накопление отходов и загрязнение окружающей среды тяжелыми металлами, органическими соединениями [1]. Топливно-энергетический комплекс создает многие экологические проблемы современности. В России около 70 \% выбросов углекислого газа в атмосферу осуществляют предприятия энергетической отрасли [2]. Основным видом промышленных отходов, занимающих одно из первых мест по объему выхода и представляющих серьезную экологическую опасность, являются золы уноса [5].

Ведущим направлением обеспечения экологической безопасности является поэтапное сокращение уровня негативного воздействия на окружающую среду отходов топливноэнергетического комплекса. Значительная площадь земель, отведенная под золошлаковые отходы, безвозвратно изымается из полезного использования, консервация их требует значительных затрат. Токсичные вещества, содержащиеся в золах уноса, такие как $\mathrm{SO}_{3}$, при взаимодействии с влагой воздуха могут образовывать сильные кислоты, которые приводят к коррозии эксплуатируемых строительных конструкций, загрязнению почв, грунтовых и поверхностных

$$
-843-
$$


вод, воздушного бассейна, представляя угрозу для окружающей среды. Агрессивные вещества, попадая в организм человека по трофическим цепям, вызывают широкий спектр тяжелейших заболеваний.

Использование золошлаковых отходов позволяет сократить их накопление и снизить нагрузку на окружающую среду. Поскольку промышленность строительных материалов является наиболее материалоемкой, то глобальное использование отходов связано именно с этой отраслью [5]. Все большее применение находит сухая зола уноса с электрофильтров ТЭЦ, получившая всеобщее признание как материал, имеющий важное значение в качестве добавки к различным бетонам, строительным растворам, керамике, тепло- и гидроизоляционным материалам [6-13].

Рассматривая данную проблему на примере г. Красноярска, где главным источником энергии служат топливосодержащие ископаемые - бурые угли, наибольшая доля произведенной тепловой энергии и, следовательно, количество отходов приходятся на ТЭЦ-1, ТЭЦ-2 и ТЭЦ-3, расположенные в черте города. Количество топлива (угля), израсходованного на получение тепловой и электрической энергии в 2007 г., представлено в табл. 1 [3, 4].

Таким образом, в год сжигается около 5 млн т угля и при этом образуется около 500 тыс. т золы и шлака.

В настоящее время в России имеется значительное количество научных разработок в части использования попутных продуктов производства для повышения качества строительных материалов. В направлении расширения сырьевой базы для производства бетонов, растворов, сухих строительных смесей работают Ю.М. Баженов, М.Н. Мороз, В.И. Калашников, И.В. Ерофеева, Ш.Н. Иохан [15-20].

Пригодность золы для изготовления вяжущих и бетонов устанавливают путем опытной проверки химического состава и содержания вредных примесей, к которым относятся несгоревшие топливо, сера, оксид кальция и магния [21-25].

Систематизацией исследований по таким видам материалов занимаются ведущие институты страны, такие как МГСУ, НИИЖБ, ЦНИИС, ВНИИСтром. Активно работают в этом направлении как российские, так и зарубежные ученые [23-27], в том числе над проблемами стабилизации структуры золы уноса [26-28].

Как показывает практика технической и технологической эксплуатации зданий и сооружений, увеличение срока службы напрямую связано с восстановлением функциональных качеств отдельных конструктивных элементов, особенно первой степени ответственности,

Таблица 1. Расход угля крупнейшими ТЭЦ г. Красноярска в 2007 г.

Table 1. Coal consumption by the largest CHP systems in Krasnoyarsk in 2007

\begin{tabular}{|c|c|}
\hline Станция & Расход угля, тыс. т \\
\hline Красноярская ТЭЦ-1 & 2373,6 \\
\hline Красноярская ТЭЦ-2 & 1978,2 \\
\hline Красноярская ТЭЦ-3 & 473,6 \\
\hline Всего & 4825,4 \\
\hline
\end{tabular}


локальный отказ которых может привести к полному или ограниченному отказу системы элементов [29].

В строительном материаловедении получили развитие теории конструирования структур композитов с использованием техногенных отходов с разработкой принципов и методологии экспериментального моделирования материалов с управляемыми свойствами и оптимизированной структурой [22-29].

Однако применение золы имеет ряд технологических проблем, из-за чего производство строительных материалов с использованием зол уноса, особенно при сгорании бурых углей, ограничено. Это связано с нестабильностью химического и минералогического состава зол, получаемых при обжиге разных пластов месторождения угля, повышенным содержанием в них оксида кальция и магния, количество которых достигает 23 \%, а также с режимами сжигания топлива, которые оказывают влияние на неоднородность строения: в одном случае больше оплавленной стекловидной фазы, в другом - повышенная пористость и др.

В связи с этим задача формирования концепции управления структурой строительных материалов с применением различных видов техногенных отходов остается чрезвычайно важной [14].

\section{Постановка задачи}

В развитии указанной концепции проведенные исследования представляли следующий алгоритм с рядом этапов:

1. Анализировался генезис техногенного продукта, определяющий его состав, структуру, состояние, свойства. Оценивалась многотоннажность отходов, анализировался химический, дисперсный состав.

2. Рассматривались методы воздействия на отходы, повышающие стабильность его состава и свойств. Отрабатывались оптимальные технологические параметры, и определялась мера стабильности характеристик и свойств изучаемого отхода для получения материала с комплексом заданных свойств.

3. Составлялись и отрабатывались экспериментальные смеси и изучались процессы структурообразования материалов. Осуществлялись лабораторные исследования продуктов современными методами.

Целью настоящей работы являлось исследование влияния механоактивации золы уноса ТЭЦ на физико-механические свойства бесцементных растворов для стабилизации ее состава и локализации вредного влияния свободных $\mathrm{CaO}$ и $\mathrm{MgO}$.

\section{Методология}

Для достижения поставленной цели анализировался элементный состав зол гидроудаления Красноярских ТЭЦ, отобранных из устройств золоудаления в течение года, на рентгенофлуоресцентном спектрометре.

Методами наблюдения и сравнения выявлена высокая неоднородность состава и строения во времени, исследованы свойства зольных суспензий при различных режимах обработки в гидродинамическом диспергаторе и продуктов твердения бесцементных составов на их основе.

$$
-845-
$$




\section{Решение поставленных задач}

Химический, минералогический и фазовый составы зол зависят от вида сжигаемого угля, условий его сжигания, способа улавливания и отбора зол из шлаков.

Химический анализ отобранных в 2016 г. зол Красноярских ТЭЦ приведен в табл. 2.

В зависимости от химического состава золы делятся по модулю основности на два класса: 1-й - Мо = 0,6 - 1,5, 2-й - Мо <0,6. По этому показателю золы ТЭЦ-2 (Мо=0,73) относятся к 1-му классу, а золы ТЭЦ-1 и ТЭЦ-3 (Мо=0,25 и 0,47 соответственно) относятся ко 2-му классу.

Основным оксидом, характеризующим золы как основные или кислые, является $\mathrm{CaO}[19$, 20]. В каменных углях с преобладанием $\mathrm{SiO}_{2}$ золы получаются кислыми, с суммарным содержанием кислых оксидов около 80 \% и более, с низким модулем основности, характеризуются пуццолановой активностью. Их используют как пуццолановую добавку либо как инертный материал.

При сжигании бурых углей Канско-Ачинского энергетического бассейна образуется высокое количество оксида кальция, в том числе свободного. Такие золы отличаются гидравлической активностью, имеют высокий модуль основности и делятся по химическому составу на:

- среднекальциевые - содержание $\mathrm{CaO}_{\text {общ. }} 20-30 \%$ и $\mathrm{CaO}_{\text {своб. }}<3 \%$;

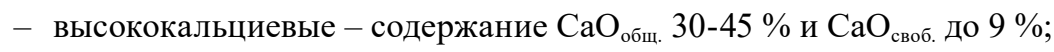

- ультра высококальциевые - содержание $\mathrm{CaO}_{\text {общ. }}>45 \%$ и $\mathrm{CaO}_{\text {своб. }}>10 \%$.

По содержанию оксида кальция золы Красноярских ТЭЦ-1 и ТЭЦ-3 относят к среднекальциевым. Зола ТЭЦ-2 является высококальциевой с высоким содержанием общего и свободного оксида кальция, характеризуется гидравлической активностью, однако из-за нестабильности режимов сжигания и образующейся стекловидной оболочки аморфной фазы может произойти разрушение затвердевшей структуры во времени вследствие поздних сроков гидратации.

Дисперсность, гидравлические и физико-механические свойства зол Красноярских ТЭЦ приведены в табл. 3.

Таблица 2. Химический состав зол Красноярских ТЭЦ

Table 2. Chemical composition of ashes of Krasnoyarsk TPPs

\begin{tabular}{|c|c|c|c|}
\hline \multirow{2}{*}{$\begin{array}{c}\text { Наименование } \\
\text { показателя }\end{array}$} & \multicolumn{3}{|c|}{ Содержание, \% по массе } \\
\cline { 2 - 4 } & $\begin{array}{c}\text { Зола Красноярской } \\
\text { ТЭЦ-1 }\end{array}$ & $\begin{array}{c}\text { Зола Красноярской } \\
\text { ТЭЦ-2 }\end{array}$ & $\begin{array}{c}\text { Зола Красноярской } \\
\text { ТЭЦ-3 }\end{array}$ \\
\hline $\mathrm{SiO}_{2}$ & 68,8 & 35,6 & 48,8 \\
\hline $\mathrm{CaO}$ & 15,2 & 28,73 & 23,0 \\
\hline $\mathrm{CaO}_{\text {своб. }}$ & 3 & $4,71-12,06$ & 5,2 \\
\hline $\mathrm{MgO}$ & 3,82 & 3,44 & 4,1 \\
\hline $\mathrm{Fe}_{2} \mathrm{O}_{3}$ & 3,57 & 8,8 & 9,3 \\
\hline $\mathrm{Al}_{2} \mathrm{O}_{3}$ & 6,22 & 8,21 & 8,2 \\
\hline $\mathrm{SO}_{3}$ & 0,93 & 3,9 & 0,7 \\
\hline $\mathrm{K}_{2} \mathrm{O}$ & 0,45 & 0,4 & 0,6 \\
\hline $\mathrm{Na}_{2} \mathrm{O}$ & 0,18 & 0,6 & 0,3 \\
\hline ппп & $<0,1$ & 1,12 & 0,7 \\
\hline Хлориды & $<0,01$ & 10,2 & 5,2 \\
\hline
\end{tabular}


Таблица 3. Свойства зол Красноярских ТЭЦ

Table 3. Ashes properties of Krasnoyarsk TPPs

\begin{tabular}{|c|c|c|c|c|c|c|c|c|c|}
\hline \multirow{3}{*}{ Место отбора золы } & \multirow{3}{*}{ 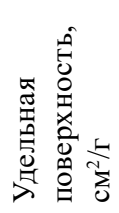 } & \multirow{3}{*}{ 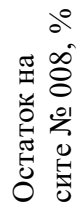 } & \multirow{3}{*}{ 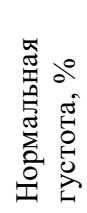 } & \multicolumn{2}{|c|}{$\begin{array}{c}\text { Сроки } \\
\text { схватывания, } \\
\text { ч-мин }\end{array}$} & \multicolumn{4}{|c|}{$\begin{array}{c}\text { Предел прочности } \\
\text { после тепловой обработки, } \\
\text { МПа }\end{array}$} \\
\hline & & & & \multirow{2}{*}{ начало } & \multirow{2}{*}{ конец } & \multicolumn{2}{|c|}{ при изгибе } & \multicolumn{2}{|c|}{ при сжатии } \\
\hline & & & & & & 1 сут & 28 сут & 1 сут & 28 сут \\
\hline Красноярская ТЭЦ-1 & 1835 & 18,8 & 25,75 & $2-25$ & $3-30$ & - & 0,75 & - & 2,4 \\
\hline Красноярская ТЭЦ-2 & 3434 & 12,1 & 26,75 & $0-30$ & $1-20$ & 1,1 & 2,4 & 6,5 & 7,95 \\
\hline Красноярская ТЭЦ-3 & 2625 & 15,8 & 32,5 & $1-10$ & $2-45$ & 0,7 & 1,02 & 2,04 & 3,32 \\
\hline
\end{tabular}

Таблица 4. Химический состав золы уноса ТЭЦ-2

Table 4. Chemical composition of CHP-2 fly ash

\begin{tabular}{|c|c|c|c|c|c|c|c|c|c|c|}
\hline \multirow{2}{*}{$\begin{array}{c}\text { № } \\
\text { пробы }\end{array}$} & \multicolumn{9}{|c|}{ Содержание оксидов, \% масс } & Стекло \\
中 & $\mathrm{SiO}_{2}$ & $\mathrm{Al}_{2} \mathrm{O}_{3}$ & $\mathrm{Fe}_{2} \mathrm{O}_{3}$ & $\mathrm{MgO}$ & $\mathrm{CaO}_{\text {общ. }}$ & $\mathrm{R}_{2} 0$ & $\mathrm{SO}_{3}$ & ппп & СаО $_{\text {своб. }}$ & фаза \\
\hline 1 & 31,31 & 4,9 & 13,79 & 5,51 & 38,27 & 0,61 & 3,25 & 2,38 & 6,89 & 43,3 \\
\hline 2 & 31,31 & 3,62 & 13,7 & 5,54 & 38,31 & 0,64 & 3,27 & 3,2 & 6,44 & 44,2 \\
\hline 3 & 31,52 & 6,65 & 13,4 & 5,29 & 35,92 & 0,64 & 2,99 & 2,98 & 8,39 & 38,9 \\
\hline 4 & 37,42 & 6,72 & 10,09 & 6,29 & 30,41 & 1,01 & 2,49 & 5,5 & 7,65 & 46,2 \\
\hline 5 & 39,01 & 6,2 & 9,65 & 6,0 & 36,14 & 0,61 & 2,1 & 3,48 & 11,89 & 40,0 \\
\hline 6 & 31,31 & 6,9 & 13,79 & 5,58 & 38,27 & 0,52 & 3,2 & 2,38 & 7,04 & 39,6 \\
\hline 7 & 43,4 & 7,02 & 10,44 & 4,5 & 30,80 & 0,7 & 2,37 & 0,97 & 7,29 & 45,0 \\
\hline 8 & 31,38 & 5,46 & 11,34 & 7,06 & 37,99 & 0,67 & 3,15 & 2,34 & 8,4 & 41,0 \\
\hline 9 & 34,62 & 6,64 & 10,59 & 8,18 & 35,27 & 0,72 & 1,14 & 2,33 & 10,69 & 40,0 \\
\hline 10 & 34,39 & 11,55 & 9,91 & 8,35 & 31,53 & 0,81 & 2,77 & 1,39 & 8,1 & 44,6 \\
\hline 11 & 30,71 & 9,56 & 9,34 & 8,18 & 37,0 & 0,58 & 1,13 & 3,26 & 4,71 & 46,01 \\
\hline 12 & 29,45 & 11,95 & 10,34 & 8,39 & 36,2 & 0,79 & 1,04 & 1,75 & 6,8 & 49,2 \\
\hline 13 & 38,64 & 9,19 & 10,37 & 6,86 & 33,3 & 0,48 & 1,41 & 2,23 & 6,54 & 44,8 \\
\hline 14 & 27,6 & 6,18 & 11,68 & 5,78 & 38,91 & 0,62 & 1,32 & 0,86 & 12,06 & 46,4 \\
\hline 15 & 32,06 & 5,66 & 11,4 & 5,69 & 38,0 & 0,67 & 3,15 & 2,4 & 8,39 & 40,5 \\
\hline 16 & 37,42 & 6,72 & 10,09 & 6,29 & 30,41 & 1,01 & 2,49 & 5,5 & 7,65 & 48,4 \\
\hline 17 & 36,7 & 6,03 & 10,42 & 5,22 & 36,36 & 0,62 & 2,27 & 2,38 & 6,89 & 38,0 \\
\hline
\end{tabular}

Из данных табл. 2, 3 видно, что наибольшей гидравлической активностью обладают золы

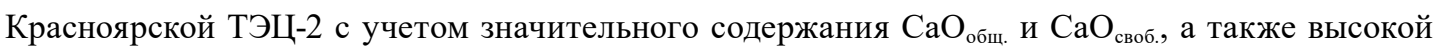
удельной поверхности, сопоставимой с дисперсностью цемента.

Существенной проблемой, из-за которой ее применение не нашло широкого распространения, является большой разброс состава и свойств. Некристаллическая фаза, или стекло, служит основным компонентом золы уноса, поэтому высокая реакционная способность высококальциевой золы уноса может быть отнесена к химическому составу стекла.

Результаты исследования состава и количества стеклофазы в пробах золы уноса ТЭЦ-2, отобранных в большом временном интервале (в течение года), приведены в табл. 4. 
Столь значительные колебания в химическом составе и строении золы ТЭЦ-2 обусловливают необходимость дополнительного воздействия на нее с помощью специальных технологических приемов в целях стабилизации состава и свойств, а также локализации вредного влияния свободного $\mathrm{CaO}$ и $\mathrm{MgO}$ как первопричины дефектов структуры камня. Для этого применяют такие методы, как предварительный помол, автоклавирование, обработка в быстроходном смесителе, гидрохимический и др., позволяющие снизить содержание $\mathrm{CaO}_{\text {своб. }}$ механически разрушить стекловидную оболочку за счет диспергирования.

Для механической обработки золы в работе использовали гидродинамический диспергатор. Принцип его действия основан на кавитационной обрабработке, в результате которой образуется однородная мелкодисперсная суспензия с микронным размером частиц. Кавитационные пузырьки, образованные локальным понижением давления жидкости, при его повышении захлопываются со сверхзвуковой скоростью, порождая ударную волну. Возникающее при этом давление, локально достигающее десятков и даже сотен тысяч атмосфер, настолько резко возрастает, что частицы золы подвергаются диспергированию с ожидаемым разрушением стекловидной оболочки частиц $\mathrm{CaO}_{\text {своб. }}$.

Для определения оптимального режима активации золы в диспергаторе исследуемыми параметрами являлись скорость и длительность обработки. При активации зольно-водной смеси получали дисперсные и однородные суспензии, вязкость которых с увеличением длительности и скорости изменялась.

Продолжительность механоактивации золы уноса в гидродинамическом диспергаторе изменяли в пределах от 1 до 5 мин при постоянной скорости 3000 об/мин.

При наименьшей продолжительности активации суспензия золы была тягучей и вязкой, поскольку процесс активации связан в первую очередь с раздроблением макроскопических частиц золы, однако с увеличением времени обработки до 3 мин становилась более подвижной, возможно, из-за высокой энергии перемешивания суспензии, а свыше 3 мин нарастала, смесь становилась жесткой, видимо, из-за значительного увеличения дисперсности частиц золы, вызывая нехватку воды затворения, и внутреннего трения, возникающего вследствие значительной диспергации частиц и взаимодействия молекул.

Для оценки влияния скорости обработки в диспергаторе золы уноса на ее физикомеханические свойства выбирали три режима - 3000, 5000 и 10000 об/мин при общей продолжительности активации 1 мин.

По мере нарастания скорости обработки наблюдалось уменьшение вязкости суспензии, что в данном случае связано с значительным увеличением дисперсности частиц золы и отделением воды. Однако при активации на скорости 10000 об/мин наблюдалось разжижение суспензии, а дальнейшие испытания продуктов твердения показали практически полное отсутствие гидратации, т. е. инертность обработанной золы уноса. Возможно, такая скорость активации привела к разрушению реакционноспособных минералов.

Для изучения влияния активации на физико-механические свойства продуктов твердения изготавливались бесцементные составы, в которых в качестве вяжущего применяли золу ТЭЦ-2. Зольно-водная смесь обрабатывалась в гидродинамическом диспергаторе с различной продолжительностью - 1, 3, 5 мин - и скоростью - 3000, 5000, 10000 об/мин. После обработки изготавливались образцы с добавлением к зольно-водной смеси мелкого песка (остаток 
Таблица 5. Физико-механические показатели продуктов твердения бесцементных составов на основе активированной золы в зависимости от продолжительности активации

Table 5. Physical and mechanical properties of hardening products of cement-free compositions based on activated ash depending on the activation duration

\begin{tabular}{|c|c|c|c|c|c|c|}
\hline \multirow[b]{2}{*}{ № п/п состава } & \multirow{2}{*}{$\begin{array}{c}\text { Время } \\
\text { активации, } \\
\text { мин }\end{array}$} & \multicolumn{3}{|c|}{ Состав } & \multirow{2}{*}{$\begin{array}{c}\text { Средняя проч } \\
\text { ность при } \\
\text { изгибе, МПа }\end{array}$} & \multirow{2}{*}{$\begin{array}{c}\text { Средняя проч } \\
\text { ность при } \\
\text { сжатии, МПа }\end{array}$} \\
\hline & & $\begin{array}{c}\text { Зола, масс. } \\
\text { части }\end{array}$ & $\begin{array}{c}\text { Песок, } \\
\text { масс. части }\end{array}$ & $\begin{array}{c}\text { Водо/ } \\
\text { вяжущее }\end{array}$ & & \\
\hline 1-в (контрольный) & - & \multirow{4}{*}{1} & \multirow{4}{*}{2} & \multirow{4}{*}{0,44} & 1,11 & 2,93 \\
\hline 2-в & 1 & & & & 1,65 & 3,86 \\
\hline 3-в & 3 & & & & 0,77 & 1,53 \\
\hline 4-в & 5 & & & & 0,07 & 1,99 \\
\hline
\end{tabular}

на сите 0,315 после просеивания) в соотношении 3:П=1:2 и водо/вяжущим $=0,44$. Формовались образцы-балочки размером 4x4x16 см, которые твердели в нормальных температурновлажностных условиях ( $\left(\mathrm{t}=20 \pm 2{ }^{\circ} \mathrm{C}, \mathrm{W}=100 \%\right)$ в течение 28 сут.

Зависимость прочностных показателей продуктов твердения от продолжительности обработки с постоянной скоростью 3000 об/мин представлена в табл. 5, а зависимость от скорости обработки с постоянным временем 1 мин - в табл. 6.

Анализ результатов табл. 5 показывает, что оптимальное время активации в гидродинамическом диспергаторе составляет 1 мин. Прочностные показатели продуктов твердения бесцементных составов на основе золы активированной в течение этого времени (состав № 2-в) повышаются на 24 \% по отношению к контрольному составу, что, очевидно, связано с разрушением стекловидной оболочки на поверхности зерен $\mathrm{CaO}$, повышением гидравлической активности золы и с равномерностью изменения объема активированной золы.

Однако дальнейшее увеличение времени активации нецелесообразно, поскольку повлекло за собой резкое снижение прочности, возможно, за счет понижения гидравлической активности золы, и увеличивало энергетические затраты.

Визуальный осмотр образцов продуктов твердения неактивированных составов (контрольный № 1-в) показал наличие волосяных и мелких трещин глубиной до 4-5 мм, возможно, из-за деструктивных процессов и неравномерного изменения объема.

Наблюдения образцов состава № 2-в, полученных с использованием золы уноса, обработанной в гидродинамическом диспергаторе в течение 1 мин со скоростью 3000 об/мин, показали отсутствие дефектов.

Более длительная обработка в диспергаторе - в течение 3 мин и более - приводит к дополнительному повышению дисперсности частиц золы до коллоидной степени, в связи с чем зольноводная смесь имеет большую вязкость при том же расходе воды затворения. Поэтому у затвердевших образцов (состав № 3-в и № 4-в) наблюдались дефекты поверхности, такие как тонкие трещины и сколы углов, возможно, вызванные усадочными явлениями в результате неполной гидратации за счет недостаточного расхода воды затворения при высокой дисперсности.

Как видно из данных табл. 6 наибольшую прочность имеют продукты твердения бесцементных составов на основе золы, активированной со скоростью 3000 об/мин. При увеличении скорости обработки у затвердевших образцов наблюдались дефекты поверхности.

$$
-849-
$$


Таблица 6. Физико-механические показатели продуктов твердения бесцементных составов на основе активированной золы в зависимости от скорости обработки

Table 6. Physical and mechanical properties of hardening products of cement-free compositions based on activated ash depending on the processing speed

\begin{tabular}{|c|c|c|c|c|c|c|}
\hline \multirow[b]{2}{*}{ № п/п состава } & \multirow{2}{*}{$\begin{array}{c}\text { Скорость } \\
\text { обработки, } \\
\text { об/мин }\end{array}$} & \multicolumn{3}{|c|}{ Состав } & \multirow{2}{*}{$\begin{array}{c}\text { Средняя } \\
\text { прочность при } \\
\text { изгибе, МПа }\end{array}$} & \multirow{2}{*}{$\begin{array}{c}\text { Средняя } \\
\text { прочность при } \\
\text { сжатии, МПа }\end{array}$} \\
\hline & & $\begin{array}{c}\text { Зола, масс. } \\
\text { части }\end{array}$ & $\begin{array}{c}\text { Песок, } \\
\text { масс. части }\end{array}$ & $\begin{array}{c}\text { Водо/ } \\
\text { вяжущее }\end{array}$ & & \\
\hline 1-с (контрольный) & - & \multirow{4}{*}{1} & \multirow{4}{*}{2} & \multirow{4}{*}{0,44} & 1,11 & 2,93 \\
\hline $2-c$ & 3000 & & & & 1,65 & 3,86 \\
\hline $3-c$ & 5000 & & & & 0,74 & 1,67 \\
\hline 4-c & 10000 & & & & 0,82 & 1,99 \\
\hline
\end{tabular}

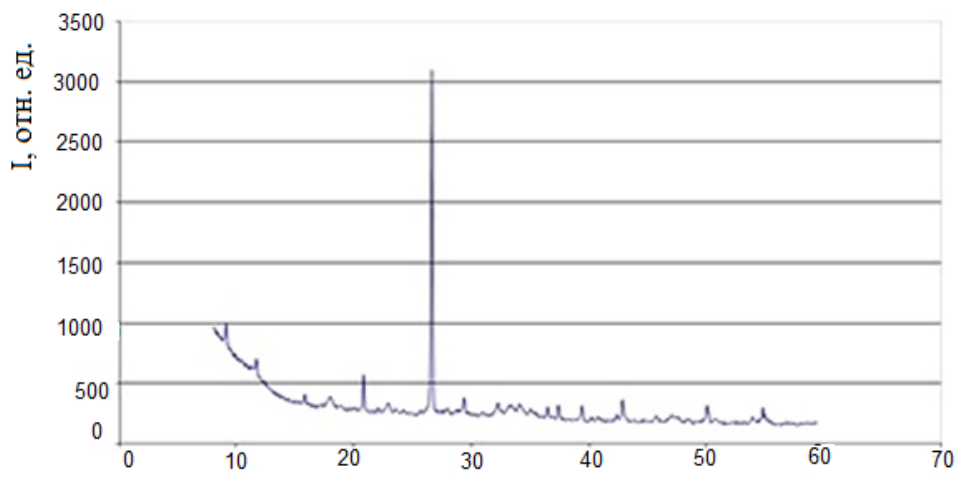

Рис. 1. Дифрактограмма продуктов твердения бесцементных составов на основе неактивированной золы (состава № 1-в (контрольный))

Fig. 1. Diffractogram of hardening products of cement-free compositions based on activated fly ash. Composition № 1-B - control

Для определения зависимости фазового состава продуктов твердения от режима обработки зольных суспензий выполнялся рентгенофазовый анализ, представленный на рис. $1-4$.

Рентгеноструктурный анализ продуктов гидратации показал, что в процессе активации зол не только происходит диспергация материала, но и поэтапно изменяется его фазовый состав. В результате деструкции появляется активная полиморфная модификация $\gamma-\mathrm{Al}_{2} \mathrm{O}_{3}$, кото-

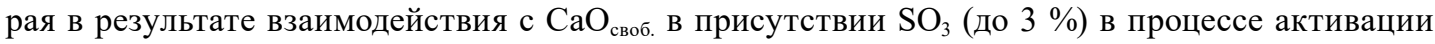
в гидродинамическом диспергаторе способствует образованию в продуктах твердения соединений типа гидросульфоалюминатов кальция, регистрируемых рентгенофазовым анализом $(\mathrm{d}=0,96$ нм$)$.

При этом могут образовываться хорошо оформленные кристаллы эттрингита, что ведет к возрастанию прочности, либо рыхлые бесформенные пучки, из которых позднее формируются иглы.

На рис. 1 наблюдается значительное количество дифракционных максимумов, определяющих большое количество различных фаз и нестабильность показателей качества золы. Дифрактограммы продуктов твердения бесцементных составов на основе активированной золы 


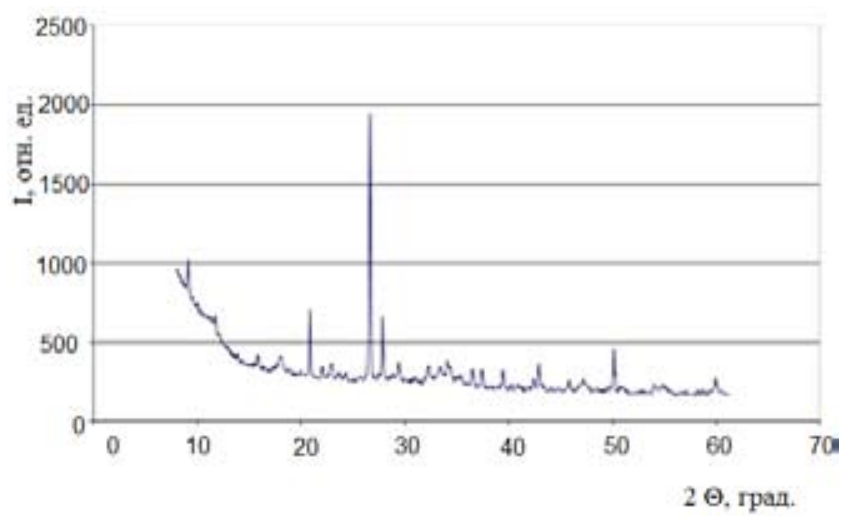

Рис. 2. Дифрактограмма продуктов твердения бесцементных составов на основе активированной золы, обработанной в гидродинамическом диспергаторе с продолжительностью 1 мин и со скоростью 3000 об/мин (состав № 2-в)

Fig. 2. Diffractogram of hardening products of cement-free compositions based on activated fly ash treated in a hydrodynamic disperser. Duration - 1 min, speed - 3000 rpm; composition № 2-в

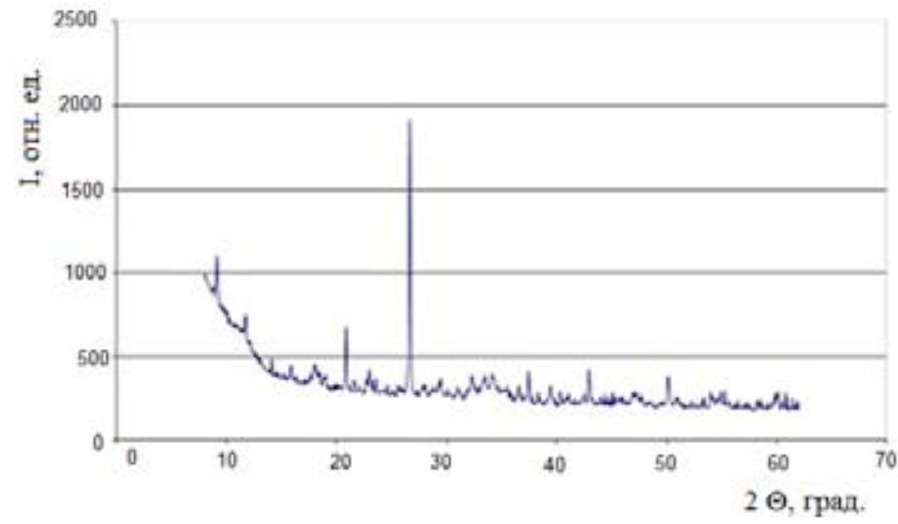

Рис. 3. Дифрактограмма продуктов твердения бесцементных составов на основе активированной золы, обработанной в гидродинамическом диспергаторе с продолжительностью 3 мин и со скоростью 3000 об/мин (состав № 3-в)

Fig. 3. Diffractogram of hardening products of cement-free compositions based on activated fly ash treated in a hydrodynamic disperser. Duration - 3 min, speed - 3000 rpm; composition № 3-в

(рис. 2-4) более однородны, с малым количеством отражений, что свидетельствует о большей гомогенности и стабильности структуры и строения.

\section{Выводы}

В результате проведенных исследований можно сделать следующие выводы.

1. Наибольшей гидравлической активностью обладают золы Красноярской ТЭЦ-2 со значительным содержанием $\mathrm{CaO}_{\text {общ. }}$ и $\mathrm{CaO}_{\text {своб., }}$ а также высокой удельной поверхностью, сопоставимой с дисперсностью цемента. Исследования состава и количества стеклофазы в пробах, отобранных в большом временном интервале (в течение года), показали, что ее количество колеблется в пределах от 40 до 50 \%. 


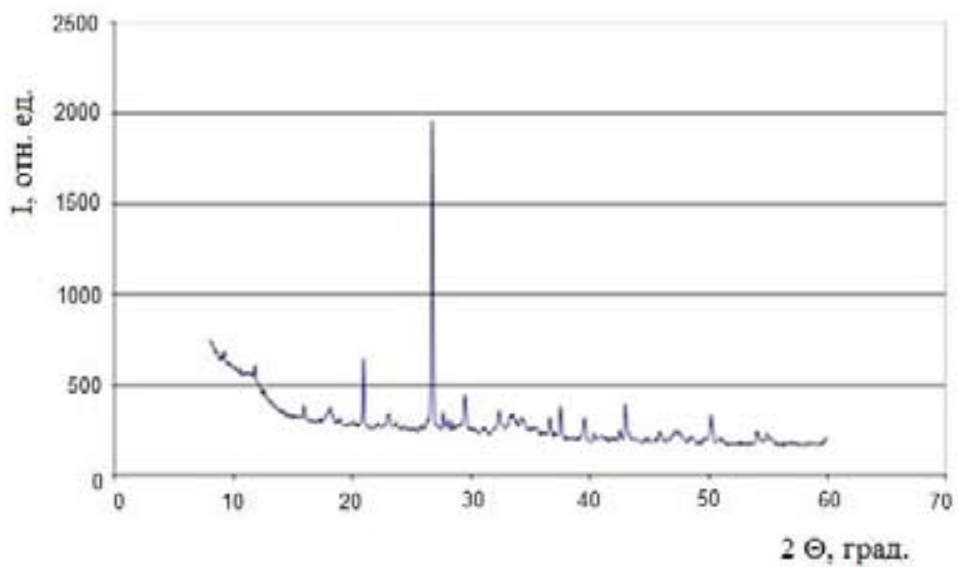

Рис. 4. Дифрактограмма продуктов твердения бесцементных составов на основе активированной золы, обработанной в гидродинамическом диспергаторе с продолжительностью 5 мин и скоростью 3000 об/ мин ( состав № 4-в)

Fig.4. Diffractogram of hardening products of cement-free compositions based on activated fly ash treated in a hydrodynamic disperser. Duration - 5 minutes, speed - $3000 \mathrm{rpm}$; composition № 4-B

2. Механоактивация зольно-водной суспензии в гидродинамическом диспергаторе

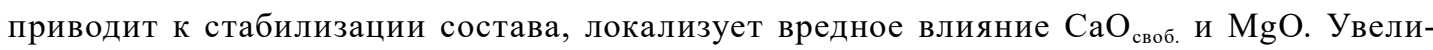
чение времени и скорости обработки влечет за собой значительное повышение дисперсности частиц золы, что вызывает нехватку воды затворения и возрастание вязкости суспензии.

3. Установлена зависимость прочностных показателей продуктов твердения бесцементных составов на основе активированной золы, фазового состава и физического состояния зольно-водных суспензий от технологических параметров гидродинамической обработки золы и возможность влияния на уровни их структуры, определяемая размерами частиц, которые участвуют в ее формировании.

Наибольшими показателями прочности при изгибе и сжатии обладали продукты твердения на основе золы, активированной в гидродинамическом диспергаторе в течение 1 мин со скоростью 3000 об/мин.

Таким образом, применение механоактивации золы уноса в гидродинамическом диспергаторе с нейтрализацией колебаний в химическом составе и структуре золы дает возможность использования ее в приготовлении бетонов или растворов с улучшением их физико-технических характеристик.

\section{Благодарность}

Исследование выполнено при финансовой поддержке РФФИ и Правительства Красноярского края в рамках научного проекта № 18-41-242008.

\section{Список литературы}

[1] Синяк Ю.В. Концепция глобального экономического развития и энергетика. Проблемы прогнозирования. МАИК, «Наука», Москва, 1998, 3, 56-73 [Sinyak Yu.V. The concept of global 
economic development and energy. Forecasting problems, MAIK, "Science", Moscow, 1998, 3, 56-73 (in Russian)]

[2] Обзор состояния и загрязнения окружающей среды в РФ за 2007 г. Росгидромет, 2008, 164 c. [Review of the state and environmental pollution in the Russian Federation for 2007. Roshydromet, 2008, 164 p (in Russian)]

[3] ОАО «Енисейская ТГК (ТГК 13) [Электронный ресурс]- Режим доступа: http://elib.sfukras.ru/handle/2311/34415 - Заглавие с экрана. [OJSC "Yenisei TGC (TGC 13) [Electronic resource]Access: http://elib.sfu-kras.ru/handle/2311/34415

[4] Экологическая эффективность технологии газификации угля на примере Красноярской агломерации [Электронный ресурс] - Режим доступа: http://modernproblems.org.ru/ecology/24hlebopros8.html - Заглавие с экрана. [Ecological efficiency of coal gasification technology on the example of Krasnoyarsk agglomeration [Electronic resource]- Access:http://modernproblems.org.ru/ ecology/24-hlebopros8.html

[5] Кузьмич Н.П. Расширение ресурсной базы строительного комплекса на основе применения местного сырья и энергоресурсоэффективных технологий. Евразийский международный научно-аналитический журнал. 2012, 2(42), 325-328 [Kuzmich N.P. Expanding the resource base of the construction complex based on the use of local raw materials and energyefficient technologies. Eurasian International Scientific Analytical Journal. 2012, 2 (42), 325-328. (in Russian)]

[6] Ежова А.И. Оценка техногенного сырья в Российской Федерации (Твердые полезные ископаемые). Горные науки и технологии. 2016, 4, 62-72. [Yezhov A.I. Evaluation of technogenic raw materials in the Russian Federation (Solid minerals). Mountain science and technology. 2016, 4, 62-72. (in Russian)]

[7] Адеева Л.Н., Борбат В.Ф. // Зола ТЭЦ - перспективное сырье для промышленности. Вестн. Ом. Ун-та. 2009, 2, 141-151 [Adeeva L.N., Borbat V.F. Zola CHPP is a promising raw material for industry. Vestn. Ohm Un-that. 2009, 2, 141-151. (in Russian)]

[8] Черепанов А.А., Кардаш В.Т. Комплексная переработка золошлаковых отходов ТЭЦ (результаты лабораторных и полупромышленных испытаний). Геология и полезные ископаемые Мирового океана. 2009, 2, 98-115 [Cherepanov A.A., Kardash V.T. Integrated processing of ash and slag waste of CHP (results of laboratory and pilot tests). Geology and minerals of the oceans. 2009, 2, 98-115. (in Russian)]

[9] Калашников В.И., Белякова Е.А., Москвин Р.Н., Мороз М.Н., Ибрагимов Р.А. Приоритетные направления в технологии бетонов. Композиционные строительные материалы. Теория и практика: сб.ст. междун. науч.-технич. конф. 2013, 39-42 [Kalashnikov V.I., Belyakova E.A., Moskvin R.N., Moroz M.N., Ibragimov R.A. Priority directions in technology of concrete. Composite building materials. Theory and Practice: Coll. international scientific tech. conf. 2013, 39-42. (in Russian)]

[10] Целыковский Ю.К. Некоторые проблемы использования золошлаковых отходов ТЭС в России. Энергетик. 1998, 7, 29-34 [Tselykovsky Yu.K. Some problems of using ash and slag waste from thermal power plants in Russia. Energetic. 1998, 7, 29-34. (in Russian)]

[11] Бабак Н.А. Геоэкологический резерв технологий, материалов и конструкций в строительстве при использовании промышленных минеральных отходов. Известия ПГУПС. 2011, 1.

$$
-853-
$$


113-119 [Babak N.A. Geoecological reserve of technologies, materials and structures in construction using industrial mineral waste. News PGUPS. 2011, 1. 113-119. (in Russian)]

[12] Целыковский Ю.К. Опыт промышленного использования золошлако- вых отходов ТЭС Ю.К. Целыковский Новое в российской энергетике. Энерго- издат. 2000, 2, 22-31 [Tselykovsky Yu.K. Experience of industrial use of ash and slag waste from thermal power plants Yu.K. Tselykovsky New in the Russian power industry. Energy Publishing. 2000, 2, 22-31. (in Russian)]

[13] Berry E.E., Malhotra V.M. Fly Ash for use in concrete - a critical review. ACIJ. 1982, 2(3), 59-73 [Berry E.E., Malhotra V.M. Fly Ash for use in concrete - a critical review. Acij. 1982, 2(3), 59-73. (in Russian)]

[14] Ватин Н.И., Петросов Д.В., Калачев А.И., Лахтинен П. Применение зол и золошлаковых отходов в строительстве. Инженерно-строительный журнал.2011, 4, 16-21 [Vatin, NI, Petrosov, DV, Kalachev, AI, Lakhtinen, P., Application of Ashes and Ashes and Slag Waste in Construction. Engineering and Construction Journal. 2011, 4, 16-21. (in Russian)]

[15] Баженов Ю.М. Новому веку новые бетоны.Строительные материаль, оборудование, технологии XXI века, 2000, 2, 10-11. [Bazhenov Yu.M. New Century New Concrete [Building materials, equipment, technologies of the XXI century, 2000, 2, 10-11. (in Russian)]

[16] Баженов Ю.М., Демьянова В.С., Калашников В.И. Модифицированные высокопрочные бетоны.М.: АCB, 2007. 368 с.[Bazhenov Yu.M., Demyanova B.C., Kalashnikov V.I. Modified highstrength concrete, Moscow, DIA, 2007, 368 p.(in Russian)]

[17] Калашников В.И., Борисов А.А., Поляков Л.Г. и др. Современные представления об использовании тонкомолотых цементов и ВНВ в бетонах, Cmpоительные материаль, 2000, 7, 12-13 [Kalashnikov V.I., Borisov A.A., Polyakov L.G. et al. Modern ideas about the use of commodities and materials and VNV in concrete, Construction materials, 2000, 7, 12-13. (in Russian)]

[18] Калашников В.И., Мороз М.Н. Высокогидрофобные многокомпонентные малошлаковые мелкозернистые бетоны Научный вестник Воронежского государственного архитектурностроительного университета. Строительство и архитектура, 2010, 1, 106-111 [Kalashnikov VI, Moroz M.N. High-hydrophobic multicomponent low-slag fine-grained concrete Scientific Herald of the Voronezh State University of Architecture and Civil Engineering. Construction and architecture, 2010, 1, 106-111. (in Russian)]

[19] Мороз М.Н., Калашников В.И., Ерофеева И.В. Эффективные бетоны нового поколения с низким удельным расходом цемента на единицу прочности. Молодой ученый, 2015, 6, 189-191 [Moroz M.N., Kalashnikov V.I., Erofeeva I.V. Effective concretes of a new generation with low specific consumption of cement per unit of strength. Young Scientist, 2015, 6, 189-191. (in Russian)]

[20] Мороз М.Н. Высокогидрофобные минеральношлаковые композиционные материалы, дис. ... канд. техн. наук. Пенза, 2007, 210 c. [Moroz M.N. Vysokovitaminnye mineralology composite materials, dis. ... kand. tech. sciences'. Penza, 2007, 210 p. (in Russian)]

[21] Пугин К.Г., Юшков В.С. Строительство автомобильных дорог с использованием техногенных материалов. Приволжский научный вестник, 2012, 4 (8), 25-30.[Pugin K.G., Yushkov V.S. Construction of roads with the use of man-made materials. Volga Scientific Herald, 2012, 4 (8), 25-30 (in Russian)] 
[22] Энтин 3.Б. Золы ТЭС-сырье для цемента и бетона. Цемент и его применение, 2012, 2, 40-46 [Entin Z.B. Ashes TES-raw materials for cement and concrete. Cement and its application, 2012, 2, 40-46 (in Russian)]

[23] Энтин 3.Б., Стржаловская Н. Еще раз о золах-уносе ТЭС. Цемент и его применение, 2009, 106-111 c. [Entin ZB, Strzhalovskaya N. Once again about the fly ash of thermal power plants. Cement and its application, 2009, 106-111 (in Russian)]

[24] Нгуен Динь Чинь, Нгуен Тхе Винь, Баженов Ю.М. Высокопрочные бетоны с комплексным применением золы рисовой шелухи, золы-уноса и суперпластификаторов. Вестник МГСУ, 2011, 1, 76-81. [Nguyen Dinh Chin, Nguyen Thé Vinh, Bazhenov Yu.M. High-strength concretes with complex use of rice husk ash, fly ash and superplasticizers. Vestnik MGSU, 2011, 1. 76-81 (in Russian)]

[25] Капустин Ф.Л. Технологические и экологические аспекты применения золы-уноса Рефтинской ГРЭС при производстве строительных материалов. Технологии бетонов, 2011, 7(8), 64-65. [Kapustin F.L. Technological and environmental aspects of the use of fly ash from the Reftinskaya GRES in the production of building materials. Concrete technology, 2011, 7(8), 64-65 (in Russian)]

[26] Рахимова Н.Р. Влияние добавок золы на свойства шлакощелочных вяжущих и бетонов. Строительные материаль, оборудование, технологии ХХІ века, 2007, 3, 36-37 [Rakhimova N.R. Effect of ash additives on the properties of slag alkaline and concrete. Building materials, equipment, technologies of the XXI century, 2007, 3, 36-37 (in Russian)]

[27] Thomas M.D.A., Bamforth P.B. Modeling Chloride Diffusion in Concrete: Effect of Fly Ash and Slag. Cement and Concrete Research, Vol. 29, 1999, 487 - 495.

[28] Сафаров К.Б., Степанова В.Ф. Регулирование реакционной способности заполнителей и повышение сульфатостойкости бетонов путем совместного применения низкокальциевой золы-уноса и высокоактивного метакаолина. Cтроительные материаль, 2016, 5, 70-73 [Safarov K.B., Stepanova V.F. Regulation of the reactivity of aggregates and increase of the sulfate resistance of concrete by the joint use of low-calcium fly ash and highly active metakaolin. Construction Materials, 2016, 5, 70-73 (in Russian)]

[29] Макаренко С.В., Коновалов Н.П. Исследование физико-химических свойств зол ТЭЦ-9 и Новой Иркутской ТЭЦ для применения в золощелочных вяжущих. Строительные материалы, 2011, 6, 60-62 [Makarenko S.V., Konovalov N.P. Investigation of the physicochemical properties of the ashes of CHP-9 and the New Irkutsk CHP for use in ash-alkali binders. Construction Materials, 2011, 6, 60-62 (in Russian)]

[30] Комплексная система утилизации ЗШМ. [Электронный ресурс]- Режим доступа: http://ksfenix.org/ - Заглавие с экрана. [Complex system of CSM utilization. [Electronic resource] Access: http://ksfenix.org

[31] ГОСТ 25818-2017 «Золы уноса тепловых электростанций для бетонов. Технические условия.». Взамен ГОСТ 25818-91; Введ. 01.03.2017. - Москва: Стандартинформ, 2017. [GOST 25818-2017 "Fly ash of thermal power plants for concrete. Technical conditions. "Instead, GOST 25818-91; Enter 03.01.2017, Moscow: Standardinform, 2017. (in Russian)] 